\title{
Anti-tumoral efficacy of therapeutic human anti-KIR antibody (Lirilumab/BMS-986015/ IPH2102) in a preclinical xenograft tumor model
}

\author{
Caroline Sola ${ }^{1}$, Fabien Chanuc ${ }^{1}$, Ariane Thielens ${ }^{1}$, Nicolas Fuseri ${ }^{1}$, Yannis Morel ${ }^{1 *}$, Mathieu Bléry ${ }^{1}$, Pascale André ${ }^{1}$ \\ Eric Vivier ${ }^{2}$, Robert Graziano ${ }^{3}$, Francois Romagne ${ }^{1}$, Cécile Bonnafous ${ }^{1}$
}

From Society for Immunotherapy of Cancer 28th Annual Meeting

National Harbor, MD, USA. 8-10 November 2013

Natural Killer cells (NK cells) are lymphocytes able to recognize and kill tumors for which the expression of Major Histocompatibility Complex (MHC) class I molecules is altered. This "missing self" recognition is mediated in humans by the lack of engagement of MHC class I i.e. Human Leucocyte Antigens (HLA) molecules with NK cell inhibitory receptors that include Killer Immunoglobulin-like Receptors (KIR). Some tumors escape NK cell immune surveillance by increasing the expression of HLA molecules on their surface. Consequently, blocking interactions between KIR and HLA molecules constitutes an interesting therapeutic strategy. The anti-KIR2DL1/2/3-specific monoclonal antibody, lirilumab/BMS-986015/IPH2102, is a human IgG4 that is being developed for treating both hematologic malignancies and solid tumors. In rodents, the MHC class I inhibitory system regulating NK cell activation is based on lectin-like family Ly49 but the KIR molecules are not expressed. The objective of this study was to develop a preclinical model to assess the efficacy of the drug candidate used in clinical trials, lirilumab. Mice expressing the human NK inhibitory KIR2DL3, on the surface of NK cells were generated on a RAG-1deficient background (KIRtgRAG mice). The human B cell lymphoma cell line, 721.221, transduced with HLA-Cw3 molecule, a ligand of KIR2DL3, was intra-venously engrafted in these mice. The expression of HLA-C by tumor cells was sufficient to allow them to escape control of NK cells, leading to mice death in around 30 days. Lirilumab treatment increased mice survival in a dose dependent manner when injected at the same time as the tumor challenge. This protective effect was NK cell-mediated and directly correlated with the duration of KIR saturation. Interestingly, lirilumab treatment also improved survival in therapeutic conditions i.e. when the antibody was injected 5 days after the tumor, also in a NK celldependent manner. In conclusion, this study showed efficacy of lirilumab as single agent in a HLA-Cw3expressing tumor model and this xenogenic pre-clinical model will be an excellent tool to investigate the therapeutic benefits of combination treatments.

\section{Authors' details}

'Innate Pharma, Marseille, France. ${ }^{2}$ Centre d'Immunologie de MarseilleLuminy, Université d'Aix-Marseille, Marseille, France. ${ }^{3}$ Bristol-Myers Squibb, Princeton, NJ, USA.

Published: 7 November 2013

doi:10.1186/2051-1426-1-S1-P40

Cite this article as: Sola et al: Anti-tumoral efficacy of therapeutic human anti-KIR antibody (Lirilumab/BMS-986015/IPH2102) in a preclinical xenograft tumor model. Journal for ImmunoTherapy of Cancer 2013 1(Suppl 1):P40.

Innate Pharma, Marseille, France

Full list of author information is available at the end of the article

( 2013 Sola et al; licensee BioMed Central Ltd. This is an Open Access article distributed under the terms of the Creative Commons Attribution License (http://creativecommons.org/licenses/by/2.0), which permits unrestricted use, distribution, and reproduction in any medium, provided the original work is properly cited. 